\section{Sounds like competition}

Various findings suggest that primary sensory areas in the cortex are not unisensory, although how stimulation of one primary area affects activity in another is unclear. Now, Medini and colleagues show that soundinduced activation of the primary auditory cortex (A1) in mice drives an inhibitory signal to the primary visual cortex (V1) that can affect visual stimulus-induced behaviour.

The authors exposed awake and lightly anaesthetized mice to $50 \mathrm{~ms}$ noise bursts and, through whole-cell recordings, showed that soundinduced activation of A1 was followed by hyperpolarizing membrane potentials in V1 layer 2/3 (L2/3) pyramidal neurons. Perfusion of A1 with muscimol to silence neural activity in this area largely blocked the sound-induced effects in V1, indicating that activation of A1 drives the inhibitory effect in V1.

To assess the neuroanatomy of the A1-V1 pathway, the authors transected the grey matter between these areas. This transection abolished sound-induced hyperpolarizing membrane potentials in $\mathrm{V} 1$, revealing that this pathway comprises corticocortical connections. Interestingly, pharmacological blockade of $\mathrm{GABA}_{\mathrm{A}}$ and $\mathrm{GABA}_{\mathrm{B}}$ receptors in $\mathrm{L} 2 / 3$ of $\mathrm{V} 1$ abolished sound-induced hyperpolarizations in pyramidal cells, indicating that the inhibitory signal from A1 to $\mathrm{V} 1$ is dependent on GABAergic transmission.

The authors also found soundinduced hyperpolarizations in pyramidal cells in L6 of V1, whereas in L5 some cells showed soundinduced depolarizing responses that preceded the hyperpolarizations that were observed in overlying L2/3 cells. They hypothesized that sound-induced hyperpolarization of $\mathrm{L} 2 / 3$ pyramidal cells is triggered by a translaminar signal that is conveyed by intragranular neurons. Using an optogenetic approach, they selectively stimulated L5 pyramidal cells in V1. This stimulation induced hyperpolarizing responses in L2/3 pyramidal cells, providing support for the authors' hypothesis. Moreover, selective silencing of L5 activity with muscimol abolished sound-driven inhibition in L2/3 pyramidal neurons.

How does A1-mediated inhibition of $\mathrm{V} 1$ affect visual responsiveness? V1 neurons in mice exposed to simultaneous visual and acoustic stimuli fired weaker action potentials than did V1 neurons in mice exposed to a visual stimulus alone. Moreover, in a behavioural assay in which mice were conditioned to show a motor response to a light flash, exposure to a sound before or simultaneously with the flash reduced the animal's motor response. This effect was dependent on sound-induced V1 inhibition, as infusion of antagonists of GABAergic transmission into V1 prevented the reduction in motor responses.

Together, these findings show that sound-driven inhibitory signals to V1 modulate visual stimulus-driven behaviour in mice. Interestingly, acoustic stimulation was also associated with hyperpolarizing responses in primary somatosensory cortex (S1), and somatosensory stimulation elicited responses in A1 and V1. This suggests that heteromodal inhibitory responses in sensory cortex are widespread, at least in mice. Visual stimulation had weaker effects on A1 and $\mathrm{S} 1$, revealing that such responses may be asymmetrical.

Darran Yates

ORIGINAL RESEARCH PAPER lurilli, G. et al. Sound-driven synaptic inhibition in primary visual cortex. Neuron 73, 814-828 (2012)

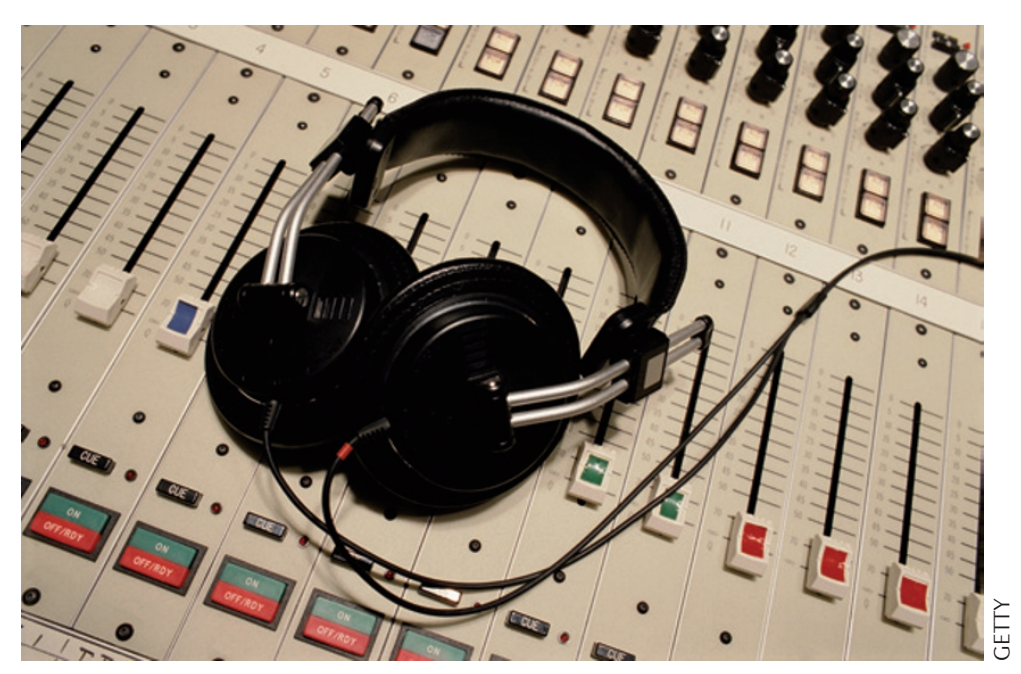

